\title{
Nutritional Anaemia and Malaria in Pre- SCHOOL AND SCHOOL AGE CHILDREN
}

\author{
C. Anumudu ${ }^{1}$, M. Afolami ${ }^{2}$, C. Igwe $^{3}$, M. Nwagwu ${ }^{1}$, and O. Keshinro ${ }^{2}$ \\ 1. Cellular Parasitology Programme, Department of Zoology, University of Ibadan, Nigeria \\ 2. Department of Human Nutrition University of Ibadan, Nigeria \\ 3. Abidagba Health Clinic, Iloti, ljebu Ode, Nigeria \\ Reprint requests to: Dr Chiaka Anumudu, Cellular Parasitology Programme, Department of Zoology, University \\ of Ibadan, Nigeria. E mail: cianumudu@yahoo.com
}

\begin{abstract}
Background: The most common cause of anemia is a deficiency of iron; but it may also be caused by deficiencies of folates, vitamin $B_{12}$ and protein. Some anemias are not caused by nutritional factors, but by congenital factors and parasitic diseases such as malaria. This study attempted to estimate the prevalence of anemia among pre-school and school- aged children in two rural areas of Odogbolu Local government area, and to determine whether its cause was nutritional or could be attributed to malaria. Methods: A total of 177 children between the ages of 2 and 11 years were included in the study. Children were examined for malaria parasites by microscopy. The World Health Organization (WHO) age-adjusted cut-off for hemoglobin and hematocrit were used to classify anemia. An enzyme linked immunosorbent assay for serum ferritin was compared with standard methods of determining iron deficiency. Under- nutrition (stunting, wasting and underweight) was classified according to the National Centre for Health Statistics standards. Values below ? - 2SD were defined as mild-moderate under-nutrition, and those below -3SD as severe malnutrition.

Results: Most of the children were anemic, 87.1\%, having PCV values below the 32\% cut-off and $95 \%$ with hemoglobin levels lower than the $11 \mathrm{~g} / \mathrm{dl}$, although parasite prevalence and density were low. Malnutrition was patent; $36 \%$ of the children were stunted, $18.3 \%$ wasted and $44.2 \%$ underweight. Serum ferritin was more sensitive than PCV in detecting anemic children. Although anemia was higher in boys and preschoolers compared to girls and school aged children, the difference was significant only in preschoolers $(P=.004)$. Anaemia was also significantly higher in Irawo village school than in lloti $(P=.0001)$
\end{abstract}

Conclusion: The anemia detected in this population may be due more to under-nutrition than to malaria.

Key words: Anaemia, nutrition, children

\begin{abstract}
Résumé
Introduction: La cause la plus fréquente de l'anémie est une carence en fer, mais elle peut aussi être causée par des carence en folates, vitamine B12 et de protéines. Certaines anémies ne sont pas causées par des facteurs nutritionnels, mais par les facteurs congénitales et les maladies parasitaires telles que le paludisme. Cette étude est pour but d'estimer la prévalence de l'anémie chez les préscolaires et les enfants d'âge scolaire dans deux zones rurales de l'administration locale d'Odogbolu, et de déterminer si sa cause est nutritionnel ou pouvaient être attribués à la malaria.

Méthodes: Un total de 117 enfants âgés entre 2 et 11 ans ont été inclus dans l'étude. Des enfants ont été étudiés pour les parasites du paludisme par microscopie. L'Organisation Mondiale de la Santé (OMS), l'âge corrigé de coupure de l'hémoglobine et l'hématocrites ont été utilisés pour classer l'anémie. L'anémie. Une enzyme ayant rapport avec immunosorben assay pour la ferritinemie a été
\end{abstract}


comparée avec les méthodes standard de la détermination de la carence en fer. La sous-alimentation (retard de croissance, émaciation et l'insuffisance pondérale) ont été classées selon le standard du Centre national pour les statistiques de la santé. Les valeurs au dessous de $\mu$ - 2SD ont été définis comme étant doux modéré, et sous-alimentation, et celles du moins de $\mu$ - 3SD comme étant la malnutrition grave.

Résultats: La plus part des enfants sont anémiques, 87,1\% ayant des valeurs PCV au dessous de $32 \%$ niveau de la limite et $95 \%$ avec des taux d'hémoglobine inférieurs à la $11 \mathrm{~g} / \mathrm{dl}$, bien que la prévalence du parasite et de la densité était faible. La malnutrition était de brevets, $36 \%$ des enfants avaient un retard de croissance. $18,3 \%$ gaspille et $44,2 \%$ d'une insuffisance pondérale. La ferritine sérique a été plus sensible que PCV dans la détection des enfants anémiques. Bien que l'anémie est plus élevé chez les garçons et préscolaires par rapport aux filles et aux enfants d'âge scolaire, la différence était significative seulement chez l'âge préscolaire $(p=0,004)$. Anémie a également été sensiblement plus élevée dans l'école du village que dans lloti ( $p=0,0001)$.

Conclusion: L'anémie détectée dans cette population est peut-être du davantage à la sous alimentation que de la malaria.

Mots-clés: Anémie, nutrition, enfants

\section{Introduction}

Iron deficiency anemia is the most prevalent form of malnutrition, affecting around $50 \%$ of pregnant women worldwide, and the eighth leading cause of disease in girls and women in developing countries. ${ }^{1}$ It has been indicated that around 600-700 million of the world's population have iron deficiency anemia by WHO criteria. ${ }^{2}$ Nutritional anemias occur frequently in both developing and industrialized countries. In industrialized countries, the prevalence of iron deficiency anemia is much lower and usually varies between $2 \%$ and $8 \%{ }^{3}$ The prevalence of iron deficiency (inclusive of anemic and non-anemic individuals) ranges from 12 to $18 \%$ in women in North America, Europe and Asia. The estimated prevalence in South East Asia is 50- 70\%. ${ }^{4}$ In females of childbearing age in poor countries, prevalence rates range from $23 \%$ in South America to $64 \%$ in South Asia. ${ }^{4}$ Prevalence rates are usually considerably higher in pregnant women, with an overall mean of $51 \%{ }^{3}$

In Nigeria, according to the UNICEF 1993 participatory information collection (PIC) studies, the prevalence rate for anemia in mothers is $24 \%$. The highest prevalence of anemia in children was recorded in South Eastern Nigeria (49.6\%) and the lowest (11 0.5\%) in North Eastern Nigeria. ${ }^{5}$ The regional variations have been attributed to high rates of worm infestations and infections in the zones with the highest prevalence. Infants, preschool age children and women of childbearing age are the groups most affected by iron deficiency. ${ }^{6,7}$ Unlike reported figures for protein energy malnutrition and vitamin A deficiency, which are declining, estimates suggest that anemia prevalence rates are increasing. ${ }^{4}$ Iron supplementation programmes have been carried out in many places throughout the world over the last two decades. Still, the prevalence of iron deficiency anemia does not appear to be declining., ${ }^{4,5}$
Body iron requirement varies from one stage in life to the other. It is very high in pre-term babies, low birth weight infants, adolescents, and in pregnancy, when it might be necessary to give an extra supply of iron. ${ }^{8}$ Recent research indicates that iron deficiency has very important implications which include poorer learning ability and behavioral abnormalities in children, lower ability to work hard, poor appetite and growth. ${ }^{3}$ Mild to moderate anemia was defined as whole blood hemoglobin concentration less than $12.0 \mathrm{~g} / \mathrm{dl}$ in mothers and less than $7.0 \mathrm{~g} / \mathrm{dl}$ in children aged 0-6years. Severe anemia was defined as whole blood hemoglobin concentrations less than $7.0 \mathrm{~g} / \mathrm{dl}$ in either mothers or children. Findings from the present study showed that the problem was more critical than presented in earlier estimates (FGN/UNICEF, 1994). The confirmatory tests that are most commonly used for the diagnosis of iron deficiency anemia are erythrocyte protoporphyrin (EP), serum ferritin (SF) and transferrin saturation (TS) tests. ${ }^{9}$

The aim of this study was to estimate the prevalence of anemia in two rural areas in Odogbolu Local Government area of Ogun State and to determine its cause - whether nutritional or due to malaria infection. Specifically, to establish whether the global trend of prevalence of anemia being higher in preschool children compared to school age children is valid in this community also.

\section{Materials and Methods}

\section{Study location}

The study was carried out in Itamapako and Irawo villages located in Odogbolu Local Government area of Ogun State. The villages are good representations of the area because they are well homogenized: there was not much difference in their style of living, culture and occupations practiced. The two study 
villages were also chosen for their proximity to the field base. The children were aged 2 to 11 years old.

\section{Sample size}

A total of 177 volunteers, 63 children from St Anne's primary school, Irawo village and 114 children from St Aloysius primary school Itamapako lloti village were included in the study. The children were chosen randomly from the schools' student enrolment registers. Pre-schoolers were sampled from the kindergarten section also available in these schools.

\section{Data collection}

Following ethical approval by the Joint UI/UCH Ethical Committee, preliminary visits were made to the schools and the head teachers instructed the pupils to obtain their parents' consent. Only children whose parents consented, and who also wanted to participate, were included in the study. The blood samples were collected by ante-cubital venipunture, by qualified personnel from the Abidagba Health Centre, into sample tubes containing anti-coagulant (citric acetate) and stored on ice for transport to the laboratory later in the day. The weight, height and mid upper arm circumference (MUAC) measurements were taken following standard procedures and necessary precautions. Information on age was obtained from the school registers and from the teachers. A questionnaire on malaria morbidity and nutritional patterns was administered to the children.

\section{Analytical procedures}

Hemoglobin estimation was done by the cyanomethemoglobin method [9]. The PCV was determined by spinning the samples in capillary tubes at $12000 \mathrm{~g}$ for 10 minutes. PCV values were then read off the microhematocrit reader. The samples were analyzed in duplicate and the mean values recorded. Nutritional status (wasting, stunting and underweight) was determined with reference to the NCHS standards. The cut off point to distinguish between normal and subnormal nutritional status was ?-2SD. Respondents with values below the cut off were grouped as mild or moderately malnourished, and those with values above ?-3SD as severely malnourished. Children were grouped as anemic or normal according to WHO ${ }^{3}$ cut offs. $\mathrm{Hb}$ below $11 \mathrm{~g} / \mathrm{dl}$ for preschoolers and $12 \mathrm{~g} / \mathrm{dl}$ for school age children and PCV below $32 \%$ for both age groups were classified as anemic.

\section{Microscopy for malaria parasites}

Blood smears from finger-pricks were used for thick films, which were stained with Giemsa for malaria parasite screening and the determination of parasite density.

\section{ELISA for serum ferritin}

An enzyme immunoassay kit for the determination of ferritin in serum (BIOTEC laboratories Ltd, UK) was used to test 93 samples from the two villages. The assay was based on the principle of a sandwich formed by the serum ferritin, which is detected between two specific monoclonal antibodies directed against two different epitopes on the serum ferritin molecule. The capturing monoclonal antibody was conjugated to biotin, while the second monoclonal antibody was labeled with horseradish peroxidase. The plates had been pre-coated with streptavidin. 20u1 of serum and ferritin standards (containing different concentrations of human liver ferritin: 0,5 , $20,100,400,1000 \mathrm{ng} / \mathrm{ml}$ in human protein buffer with gentamycin) were added to all but the blank wells in row A. I00ul of a preparation containing the two monoclonal antibodies to ferritin were also added and the whole incubated at room temperature for 1 hour. Afterwards, plates were washed $5 \times$ with PBS/Tween 20. The chromogen, tetramethylbenzidine (TMB) was mixed in equal volume with the substrate solution containing stabilized hydrogen peroxide, and $200 \mathrm{u}$ was dispensed into the wells. After incubation at room temperature $\left(29^{\circ} \mathrm{C}\right)$ for $10 \mathrm{~min}$ in the dark, $100 \mathrm{ul}$ of IN hydrochloric acid was added to stop the color reaction. Plates were read at an absorbance of $405 \mathrm{~nm}$. Absorbance values were converted to $\mathrm{ng}$ concentration by reading off the ferritin standard (dose response) curve (Figure 1).

\section{Statistical analysis}

Regression and correlation analysis to determine the relationship between anemia and wasting stunting and underweight, were carried out using the SPSS software. Each of the dependent variables PCV, $\mathrm{Hb}$ and MUAC was regressed on the dummy variables of normal, mild- moderate and severe malnutrition as arrived at using the categories of weight for height $(W / H)$, height for age $(H / A)$ and weight for age $(W / A)$. The models allowed us to know if there was any significant difference between the PCV, $\mathrm{Hb}$ and MUAC of normal and malnourished children.

Given the three categories, two dummy variables were introduced into the regression model to avoid perfect co- linearity of regressors. The category of normal nutritional status was used as the base dummy, in order to allow the directly estimated coefficients of the dummy variables in the model to be estimated as the deviation in the level of the dependent variable of the normal from that of the category in question.

\section{Results}

Serum samples from children 2-11 years old were analyzed using PCV, $\mathrm{Hb}$ and serum ferritin levels 
for anemia, and their nutritional status determined by standard anthropometric parameters. The children were grouped as preschoolers, (below $6 y e a r s$ ) and school age (above 6years old). The mean ages for the two groups were 47months (4yrs) for preschoolers $(n=75)$ and 89 months for school age children $(\mathrm{n}=96)$.

PCV values were obtained for 163 of 177 subjects (Figure 2). Using the WHO criteria, where the cutoff for determination of anemia was PCV less than $32 \%, 21$ of 163 children (12.9\%) were normal and 142 of 163 children (87.1\%) were anemic. The degree of anemia was based on the percentiles. PCV values within $90 \%-95 \%$ of the cut off point (32\%) were categorized as mild anemia ie, (13\%). Values within $80 \%-89 \%$ of the PCV cut off were grouped as moderate anemia: (32\%), and values less than $80 \%$ of the cut off were severe anemia (22\%).

The level of anemia in preschoolers (92\%) was higher than in school-aged children (63\%; $P=.004$, Figure 3). Anaemia in boys (91.5\%) was higher than in girls (85\%), and higher in St Anne's primary school Irawo (91.7\%) than in St Aloysius primary school Iloti (85\%). These differences were not significant.

Table 1. Summary of frequencies for the nutritional status of the subjects

\begin{tabular}{|c|c|c|c|}
\hline Types and degree of malnutrition & No. & $\%$ & $\%$ Prevalence \\
\hline \multicolumn{4}{|l|}{ Stunting } \\
\hline Normal & 110 & 64.0 & \multirow{3}{*}{35} \\
\hline Mild-moderate & 11 & 6.3 & \\
\hline Severe & 51 & 29.7 & \\
\hline \multicolumn{4}{|l|}{ Wasting } \\
\hline Normal & 143 & 81.7 & \multirow{3}{*}{18.3} \\
\hline Mild-moderate & 27 & 15.4 & \\
\hline Severe & 5 & 2.9 & \\
\hline \multicolumn{4}{|l|}{ Underweight } \\
\hline Normal & 96 & 55.8 & \multirow{3}{*}{44.2} \\
\hline Mild-moderate & 14 & 8.2 & \\
\hline Severe & 62 & 36.0 & \\
\hline
\end{tabular}

Data from 172 subjects was used to determine the nutritional status based on underweight and stunting ie, W/A and $\mathrm{H} / \mathrm{A}$ respectively (Table 1 ). $36 \%$ of the children were stunted, $18.3 \%$ wasted and $44.2 \%$ underweight. Underweight was the most prevalent form of malnutrition, while the most severe form was stunting. There was a significant positive correlation between stunting and underweight $(P=.0000)$. Regression analysis showed that mid-upper arm circumference (MUAC) differed significantly between children with a normal nutritional status and those severely malnourished $(P=.005)$. The MUAC correlated negatively with $\mathrm{PCV}$, stunting, $\mathrm{Hb}$, underweight, wasting and sex (was significant only for PCV and wasting).

The hemoglobin values were significantly different between normal and mild-moderate malnourished children. Most of the children had no malaria parasites, and mean parasite density for those parasitaemic in the two age groups were similar 461 and 463 parasites /ul blood.

The serum ferritin ELISAs were more sensitive than PCV in detecting anemic children. About $9 \%$ (9/93) had serum ferritin values near normal ie, less than $10 \mathrm{ug} / \mathrm{ml}$. Serum ferritin concentration was significantly lower among children in the lloti school $(1 / 0 \mathrm{ng} / \mathrm{ml})$ than among children in the Irawo school $(175 \mathrm{ng} / \mathrm{ml})(P=.003)$. Serum ferritin concentration did not correlate with the presence of malaria parasites, so anemia in this population is probably not due to current Plasmodium falciparum infections. There was no significant difference in serum ferritin values in preschoolers $(150 \mathrm{ng} / \mathrm{ml})$ and school age children (II5ng/ml), both groups were anemic.

\section{Discussion}

The level of anemia in preschool children (92\%) was higher than that in school- aged children (62.5\%); a trend similar to those reported in the 4th world Nutrition Situation Report. ${ }^{10}$ This high rate may be indicative of the fact that the diet of the preschoolers is not adequate for their iron needs. Interviews carried out during these studies, with the children, and observations by the community health workers revealed that the staple food of this area is garri. Farming is the major occupation and only crops that are likely to yield some income are planted. The level of income of family breadwinners is also low, judging by their houses and the yield from their farms. Their financial access to meat and other good animal sources of iron is therefore very limited. Efforts by the public health workers in the health centre in Iloti to encourage the mothers to have home vegetable gardens have not met with much success. These reasons could account for the very high prevalence of anemia observed in the study area. 
Figure 1. Standard curve for serum ferritin

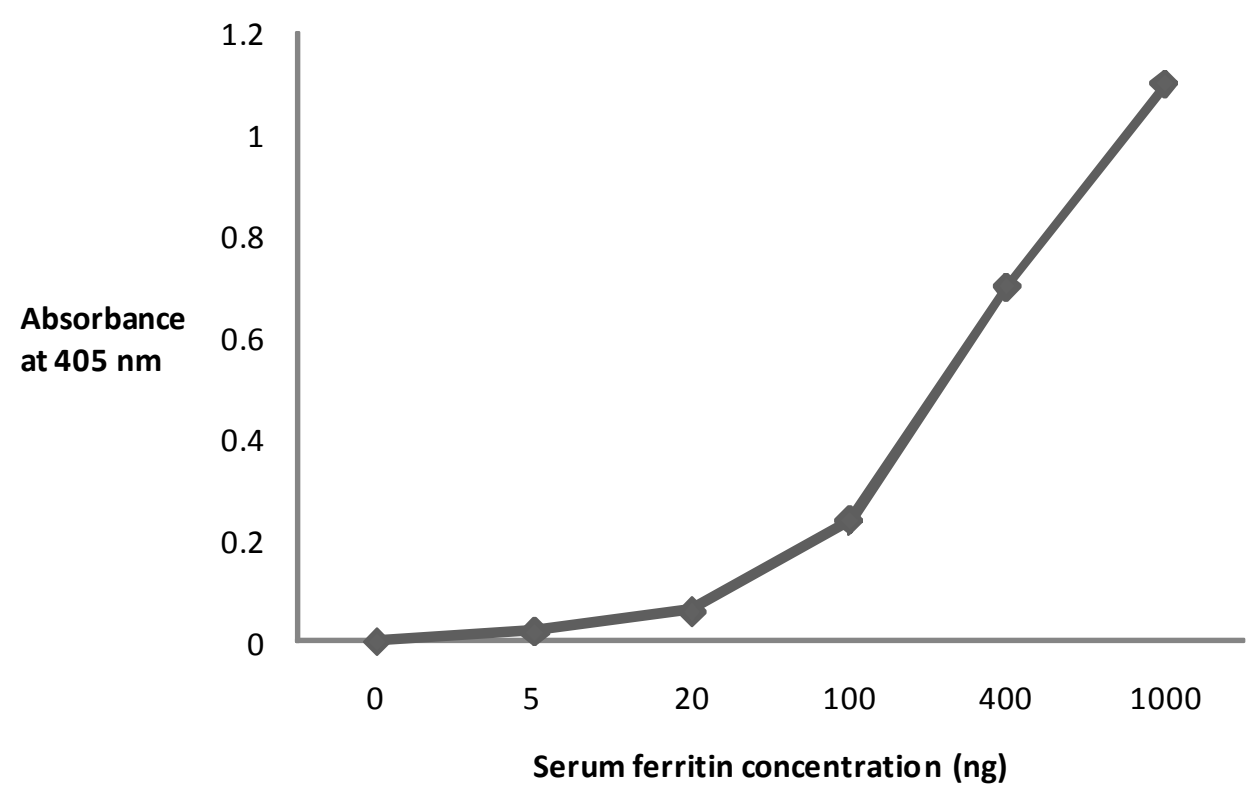

Figure 2. Frequency distribution of PCV of subjects

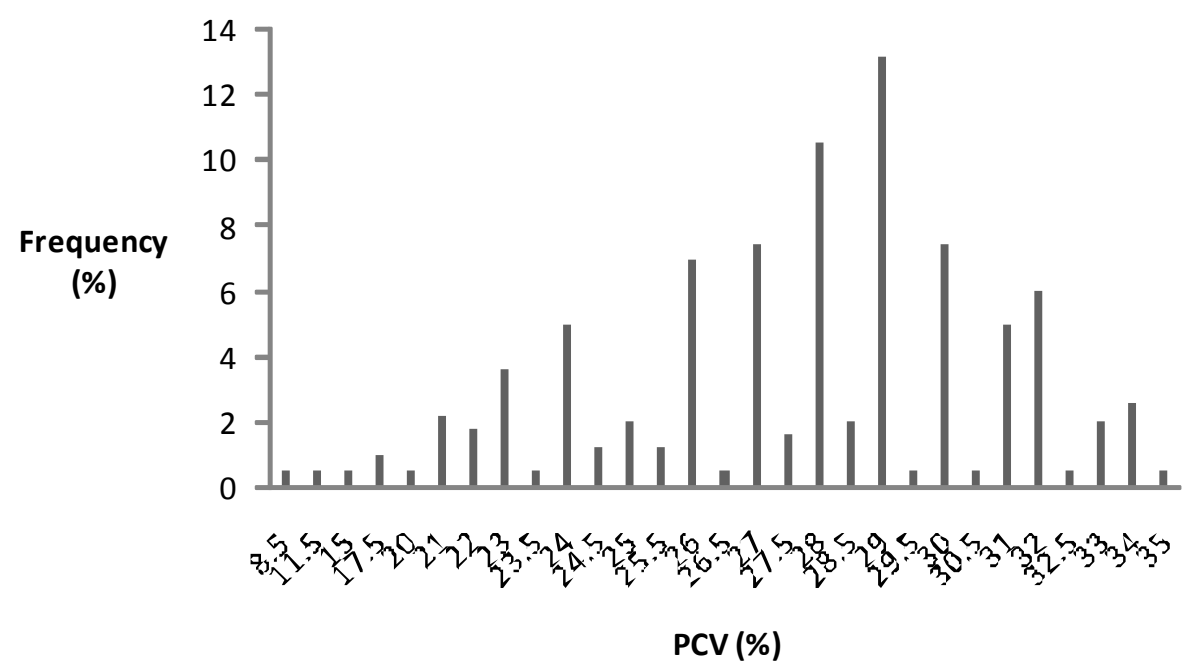

Figure 3. Anaemia prevalence in pre-school and school-aged children

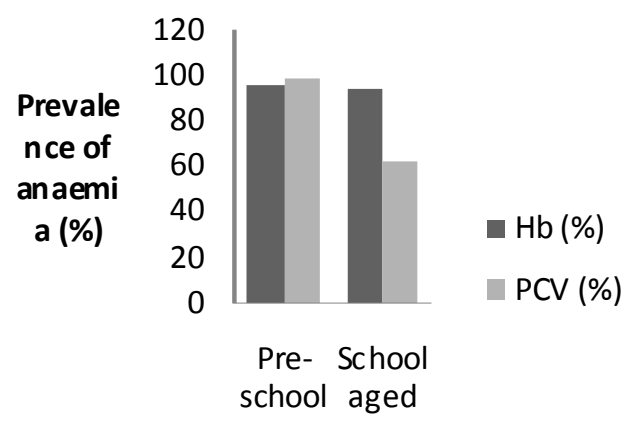

Age group

The WHO cut offs may be too high. There is a long-standing debate over the appropriateness of the WHO cutoffs for diagnosing anemia in Africans and African - Americans who may have systematically lower hemoglobin values than Caucasians with comparable iron status. ${ }^{11}$ Using the WHO cutoffs significantly overestimate anemia prevalence in Africans and African-Americans. Some workers have expressed a need for population- specific criteria for hemoglobin and anemia, but no firm recommendations have been made. ${ }^{12-14} \mathrm{~A}$ recent report ${ }^{15}$ questioned the current criteria for the diagnosis of anemia, and suggested that these be reviewed and revised to link them explicitly to functional outcomes of public health significance. A method for determining population- specific hemoglobin cutoffs was proposed ${ }^{11}$ a cut off of $10.7 \mathrm{~g} / \mathrm{dl}$ for Jamaican girls aged $13-14$ years. This is $2.7 \%$ less than the WHO cut off for a similar age group. Using this cut off to estimate anemia in the present study, anemia prevalence reduces to $89 \%$ from $95 \%$. Direct comparison of the anemia prevalence in this study with others was hampered 
because of differences in available measures and methods, as well as by the fact that there are limited documented studies done on similar age groups in Nigeria. ${ }^{16,17}$ However, some comparison can be made. Severe anemia was defined as whole blood hemoglobin less than $7.0 \mathrm{~g} / \mathrm{dl}$ in either mothers or children. If this cutoff were used for the present study population, the prevalence rate of severe anemia would reduce drastically from $21.6 \%$ to about $2 \%$. Thus using the WHO cut off criteria for Africans and African Americans could inadvertently lead to an overestimation of anemia prevalence.

The anemia prevalence levels in this study area $(92 \%$ and $62 \%)$ are much higher than the current ${ }^{10}$ prevalence levels for developing countries ( $42 \%$ and $53 \%)$ for preschool and school aged children respectively. However, the preschool data should be interpreted with care as the prevalence estimates are based on a limited number of surveys, mostly carried out in North and Latin America ${ }^{10}$; thus those populations may not be considered representative of developing countries.

The commonest form of malnutrition in the children in the present study was underweight (44\%) followed by stunting (36\%) and wasting (18\%). The prevalence of stunting in this study (36\%) was similar to that estimated in the 4th World Nutrition Situation Report for the West African sub-region (34.9\%). The estimated prevalence of underweight in this study is higher than the current rate for West Africa $(36.5 \%) .{ }^{10}$ Even though underweight affects fewer children globally than stunting, ${ }^{10}$ West Africa has seen an increase of $0.32 \%$ per year in recent years. Wasting is not as common as stunting and underweight in any region of the world and a similar pattern is observed in the results of this study. West Africa has a wasting prevalence of $15.5 \%$ and in this study, $18.3 \%$. There has been a substantial increase in wasting among West African children, and this increase could explain the high rate of underweight in these countries.

Chronic malnutrition appeared to be a more pressing problem than acute malnutrition as indicated by the levels of stunting and underweight compared to the levels of wasting,

and the higher prevalence of anemia in preschool than in school age children. It is necessary therefore, to educate the mothers in this study area on the importance of feeding their children appropriately from their early life. There were significant differences in the MUAC of normal children and wasting and underweight children, suggesting that MUAC could be accurately used for rapid assessment of on-going malnutrition in specific populations, since it will be easier to establish local standards. The significant correlation between MUAC and PCV, underweight and wasting also supports this argument.
Serum ferritin levels, as measured by ELISA can be reliably used to diagnose anemia, as this study has shown. The test for it is very sensitive and easily done. It has also been shown that nutritional status can modulate malaria morbidity and mortality. ${ }^{18}$ There was no association between serum ferritin values and the presence of malaria parasites in this study; this suggests that the anemia measured in this population may have been due mostly to nutrition basis. This conclusion is confirmed by work done in Lagos, ${ }^{17}$ which showed that ferritin levels were significantly higher in subjects with high densities of malaria parasites.

\section{Acknowledgment}

We thank the staff and students of the schools in Irawo and Iloti, and the Paula Adjama of the Iroto Rural development Centre.

\section{References}

1. World Bank. World development report. Investing in health. Oxford University Press, Oxford, 1993.

2. De Meyer M. Adiels-Tegman, Rayston E. The prevalence of anaemia in the World. World Health Stat. 1985;38:302-316.

3. Latham M. Human Nutrition in the developing world. FAO Publications, Rome, 1997.

4. UN/ACC/SCN. Second report on the world nutrition situation. Global and regional reports. Geneva, 1985.

5. FGN/UNICEF The nutritional status of women and children in Nigeria. UNICEF. Lagos, 1994.

6. Dallman PR, Reeves JD. Laboratory diagnosis of iron deficiency anaemia. In Iron Nutrition in infancy and childhood. Nestle Nutrition 1984; 1220.

7. UN/ACC/SCN. Controlling iron deficiency. ACC/SCN state-of-the-art series. Geneva ACC/SCN, 1991; (Nutrition policy discussion paper no. 9.)

8. Dallman R. Present knowledge in nutrition. ILSI Press. Washington, 1991.

9. Cartwright GE. Diagnostic laboratory haematology. Grunne and Stratton. New York, 1968.

10. UN/ACC/SCN. 4th report on World nutrition Situation ACC/SCN, Geneva, 2000.

11. Himes JH, Walker SP, Williams S, Bennett F, Grantham-McGregor SM. A method to estimate prevalence of iron deficiency and iron deficiency anaemia in adolescent Jamaican girls. Am J Clin Nutr. 1997;65:831-836.

12. Johnson - Spear MA. Yip R. Haemoglobm difference between black and white women with comparable iron status: justification for race 
specific criteria. Am J Clin Nutr. 1994;60:117-121.

13. Dallman PR, Barr GD, Allen CM, Shinefield HR. Haemoglobin concentration in white, black and Oriental children: is there need for separate criteria in screening for anaemia? Am J Clin Nutr. 1978;31:377-380.

14. Meyers LD, Habicht J-P, Johnson CL, Brownie C. Prevalence of anaemia and iron deficiency anaemia in black and white women in the United States estimated by two methods. Am J Public Health. 1983;73:1042-1049.

15. Beaton G, McCabe G. Efficacy of intermittent iron supplementation in the control of iron deficiency anaemia in developing countries: an analysis of experience. Final report on the micronutrient initiative Ottawa. ACC/SCN Geneva, 1999.

16. Abidoye KO, Osibogun AO, Oduwole MD. Assessment of haemoglobin level of the infants attending government clinics in Sagamu, Lagos environs, Nigeria. Nutr Res. 1997;17:581-589.

17. Odunukwe NN, Salako LA, Okanny C, et al. Serum ferritin and other haematological measurements in apparently healthy children with malaria parasitaemia in Lagos, Nigeria. West Afr J Med. 2001;29:42-45.

18. Shankar AH. Nutritional modulation of malaria morbidity and mortality. J Infect Dis. 2000;182:S37-S53. 